\title{
Excessive Expression of Acetylcholinesterase Impairs Glutamatergic Synaptogenesis in Hippocampal Neurons
}

\author{
Haiheng Dong, ${ }^{1,2}$ Yun-Yan Xiang, ${ }^{1,2}$ Noa Farchi, ${ }^{4,5}$ William Ju, ${ }^{3}$ Yaojiong Wu, ${ }^{1,3}$ Liwen Chen, ${ }^{1,3}$ Yutian Wang, ${ }^{3}$ \\ Binyamin Hochner, ${ }^{4}$ Burton Yang, ${ }^{1,3}$ Hermona Soreq, ${ }^{5}$ and Wei-Yang $\mathbf{L u}{ }^{1,2}$ \\ ${ }^{1}$ Sunnybrook and Women's College Health Sciences Centre, Departments of ${ }^{2}$ Anesthesia, ${ }^{3}$ Laboratory Medicine, and Pathobiology, University of Toronto, \\ Toronto, Ontario, Canada M4N 3M5, Departments of ${ }^{4}$ Neurobiology and ${ }^{5}$ Biological Chemistry, Institute of Life Sciences, and The Israel Center for \\ Neuronal Computation, The Hebrew University of Jerusalem, Israel 91905
}

Acetylcholinesterase (AChE) exerts noncatalytic activities on neural cell differentiation, adhesion, and neuritogenesis independently of its catalytic function. The noncatalytic functions of AChE have been attributed to its peripheral anionic site (PAS)-mediated proteinprotein interactions. Structurally, AChE is highly homologous to the extracellular domain of neuroligin, a postsynaptic transmembrane molecule that interacts with presynaptic $\beta$-neurexins, thus facilitating synaptic formation and maturation. Potential effects of AChE expression on synaptic transmission, however, remain unknown. Using electrophysiology, immunocytochemistry, and molecular biological approaches, this study investigated the role of AChE in the regulation of synaptic formation and functions. We found that AChE was highly expressed in cultured embryonic hippocampal neurons at early culture days, particularly in dendritic compartments including the growth cone. Subsequently, the expression level of AChE declined, whereas synaptic activity and synaptic proteins progressively increased. Chronic blockade of the PAS of AChE with specific inhibitors selectively impaired glutamatergic functions and excitatory synaptic structures independently of cholinergic activation, while inducing AChE overexpression. Moreover, the PAS blockade-induced glutamatergic impairments were associated with a depressed expression of $\beta$-neurexins and an accumulation of other synaptic proteins, including neuroligins, and were mostly preventable by antisense suppression of AChE expression. Our findings demonstrate that interference with the nonenzymatic features of $\mathrm{AChE}$ alters $\mathrm{AChE}$ expression, which impairs excitatory synaptic structure and functions.

Key words: anticholinesterase; cytoarchitecture; growth cone; neurexin; neuroligin; peripheral anion site

\section{Introduction}

Acetylcholinesterase (AChE) is expressed in the cortex (Geula et al., 1995) and hippocampus (Aubert et al., 1994). Its fundamental role at cholinergic synapses is to terminate neurotransmission by rapid hydrolysis of acetylcholine (Massoulie, 2002). Independent of its catalytic function, AChE exhibits multiple biological actions on neuronal cell differentiation (Schlaggar et al., 1993; Coleman and Taylor, 1996), adhesion (Johnson and Moore, 2000; Sharma et al., 2001), neuritogenesis (Koenigsberger et al., 1997; Grifman et al., 1998; Bigbee et al., 2000), and neurodegeneration in some pathological processes, such as Alzheimer's disease (Rasool et al., 1986; Parnetti et al., 2002). Excess AChE emerges under conditions of stress (Meshorer et al., 2002; Nijholt et al., 2004) and exposure to AChE inhibitors (Kaufer et al., 1998). The corresponding changes in synaptic structure and transmission are as yet unexplored.

Received May 31, 2004; revised July 20, 2004; accepted Aug. 12, 2004.

This study was supported by the Canadian Institutes of Health Research (CIHR) and Canadian Neurotrauma Research Program (W.-Y.L.), J. P. Bickell (W.-Y.L.), and Ester Neuroscience (H.S.). W.-Y.L. is a CIHR New Investigator and a recipient of a New Opportunities award from the Canadian Foundation for Innovation.

Correspondence should be addressed to Wei-Yang Lu, Neuroscience Research Program, Research Building, Room S104, Sunnybrook and Women's College Health Sciences Centre, 2075 Bayview Avenue, Toronto, Ontario, Canada M4N 3M5. E-mail: weiyang.lu@swchsc.on.ca.

DOI:10.1523/JNEUROSCI.2106-04.2004

Copyright $\odot 2004$ Society for Neuroscience $\quad$ 0270-6474/04/248950-11\$15.00/0
In the mammalian brain, alternative splicing of the ACHE gene allows the production of two 3 '-distinct AChE variants: the "synaptic" (S) and "readthrough" (R) isoforms (Soreq and Seidman, 2001). The two AChE variants possess the same catalytic domain but differ in their $\mathrm{C}$-terminal peptides that determine their potential multisubunit assembly and heterologous association with noncatalytic subunits (Massoulie et al., 1998). Single AChE molecules possess two sites of ligand interactions: an active (hydrolytic) site at the base of a deep narrow gorge (Nair et al., 1994) and a peripheral anionic site (PAS) that consists of a group of negatively charged surface residues surrounding the entrance of the gorge (Barak et al., 1994; Botti et al., 1998). The neuritogenic action of AChE is primarily attributed to its PAS-mediated cell adhesion, because it is blocked by peripheral, but not by active, site inhibitors-ligands (Layer et al., 1993; Munoz et al., 1999). With regard to a possible role of AChE in synaptogenesis (Soreq and Seidman, 2001), the biological actions of neuroligin, a transmembrane protein that is specifically located in the excitatory postsynaptic membrane (Song et al., 1999), have become a focus of interest, because the extracellular domain of neuroligins shares a high sequence homology with AChE (Scholl and Scheiffele, 2003). With its AChE-homologous domain, neuroligins critically participate in excitatory synaptic maturation and maintenance by tightly binding to the presynaptic receptor $\beta$-neurexin (Ichtchenko et al., 1995). Interestingly, the 
neurexin- $1 \beta$ mRNA is drastically lower in embryonic transgenic mice that overexpress AChE compared with wild-type animals (Andres et al., 1997), suggesting that AChE levels regulate neurexin expression.

The purpose of this study was to investigate the role of AChE in synaptogenesis. We found that AChE was highly expressed in cultured embryonic hippocampal neurons, particularly in the growth cone, at early culture days. The AChE expression level gradually declined, whereas synaptic proteins progressively increased. The selective blockade of the PAS of AChE induced an overexpression of AChE, which was accompanied by specifically suppressed glutamate receptor-mediated currents, altered expression levels of synaptic proteins, and impaired synaptic structure and transmission. The PAS blockade-induced impairment of glutamatergic synaptic functions was independent of cholinergic activation and could be essentially prevented by antisense suppression of AChE expression, implying a causal involvement of excessive $\mathrm{AChE}$ expression in this regulatory process.

\section{Materials and Methods}

Primary cell culture. Dissociated embryonic hippocampal neurons were prepared from Sprague Dawley rat embryos at day 18. Briefly, neurons were dissociated from fetal hippocampi using mechanical trituration in HBSS containing $0.5 \%$ glucose, $2 \%$ sucrose, $1 \mathrm{~mm}$ sodium pyruvate, and $15 \mathrm{~mm}$ HEPES, was suspended in B27-supplemented Neurobasal medium (Invitrogen, Carlsbad, CA), with $0.5 \mathrm{~mm}$ L-glutamine, $25 \mu \mathrm{M}$ glutamic acid, $0.5 \mathrm{~mm}$ sodium pyruvate, and $0.5 \% \mathrm{FBS}$, and was then plated on poly-D-lysine-coated $35 \mathrm{~mm}$ culture dishes or 18 -mm-diameter round glass coverslips. One day after plating, the plating medium was replaced with maintenance medium made up of Neurobasal medium, 1:50 B27 supplement, and $0.5 \mathrm{~mm}$ L-glutamine. Serum was not used in the maintenance medium because serum contains high and variable concentrations of AChE (Saxena et al., 2003). Consistent with a previous report (Brewer, 1995), only a small number of the glial cells existed in the culture under this condition.

Cell treatments. Unless specified otherwise, neurons were treated on the 3 rd or the 5th day in culture (DIC) with structurally distinct positively charged PAS ligands, including 1,5-bis (4-allydimethylammoniumphenyl) pentan-3-one dibromide (BW284c51) (3-10 $\mu \mathrm{M})$, decamethonium $(50-150 \mu \mathrm{M})$, or the snake-venom toxin fasciculin-II (50$200 \mathrm{nM}$ ), in parallel, for $3 \mathrm{~d}$. As measured by Ellman's method (Ellman et al., 1961), the AChE activity in the neuronal culture medium was inhibited by $92.5 \pm 5$ or $98.5 \pm 1 \%$ of control by 3 or $10 \mu \mathrm{M}$ BW284c51, respectively. As control experiments, the active site AChE inhibitor physostigmine $(10 \mu \mathrm{M})$, nicotinic acetylcholine receptor (AChR) antagonist mecamylamine $(20 \mu \mathrm{M})$, muscarinic AChR antagonist atropine $(10 \mu \mathrm{M})$, or AChR agonist carbachol $(50 \mu \mathrm{M})$ were also used, respectively, for treating the culture in the same way. In some experiments, the mouse AChE antisense EN101 (12 $\mu \mathrm{g} / \mathrm{ml})$ (Shohami et al., 2000; Brenner et al., $2003)$ and an inverse oligonucleotide INV101 (12 $\mu \mathrm{g} / \mathrm{ml})$ (Shohami et al., 2000; Brenner et al., 2003) as a control were added in the culture medium together with BW284c51. To investigate the effect of excess $\mathrm{AChE}$ on the function of neurons, recombinant human AChE (0.5-3.0 $\mathrm{U} / \mathrm{ml}$ ) was added to some cultures on the 4th DIC. Physostigmine (10 $\mu \mathrm{M}$ ) was added to the AChE-treated culture at the same time to eliminate a possible cholinergic action by the excess AChE. As controls, some sister dishes were treated only with physostigmine. Fasciculin-II and tetrodotoxin (TTX) were purchased from Alomone Labs (Jerusalem, Israel), and other reagents used for the treatments were from Sigma-Aldrich Canada (Oakville, Canada).

Patch-clamp recordings. To study the effect of the aforementioned treatments on functions of major transmitter receptors in hippocampal neurons, glutamate- and GABA-evoked transmembrane currents were evaluated. Conventional whole-cell recordings were made in the cultured neurons on the 6th or the 8th DIC, unless otherwise specified. Neurons in treated and sister-control dishes were randomly selected under conventional microscopy. Recordings were performed under voltage clamp (at $-60 \mathrm{mV}$ ) with an Axopatch-1D amplifier (Axon Instruments, Foster City, CA). Electrodes (3-4 M $\Omega$ ) were constructed from thinwalled glass ( $1.5 \mathrm{~mm}$ diameter; World Precision Instruments, Sarasota, FL) using a two-stage puller (PP-830; Narishige, East Meadow, NY). The extracellular solution (ECS) was composed of the following (in mM): 145 $\mathrm{NaCl}, 1.3 \mathrm{CaCl}_{2}, 5.4 \mathrm{KCl}, 25 \mathrm{HEPES}$, and 33 glucose, $\mathrm{pH} 7.4$ (osmolarity, $315 \mathrm{mOsm}$ ). The standard intracellular solution (ICS) for recording electrodes consisted of the following (in mM): $140 \mathrm{CsF}, 35 \mathrm{CsOH}, 10 \mathrm{HEPES}$, $2 \mathrm{MgCl}_{2}, 1 \mathrm{CaCl}_{2}, 2$ tetraethylammonium, and 4 ATP, pH 7.35 (osmolarity, $315 \mathrm{mOsm}$ ). For recording the GABA current, the ICS contained the following (in mM): $150 \mathrm{KCl}, 10 \mathrm{HEPES}, 1 \mathrm{CaCl}_{2}, 2 \mathrm{MgCl}_{2}$, and $4 \mathrm{ATP}$. Rapid application of the receptor agonists to the cells was achieved by means of a computer-controlled multibarrel perfusion system (SF-77B; Warner Instruments, Hamden, CT). The evoked electrical signal was digitized, filtered $(1 \mathrm{kHz})$, and acquired on-line using the program pClamp (Axon Instruments). For recording of miniature EPSCs (mEPSCs), $0.5 \mu \mathrm{M}$ TTX and $20 \mu \mathrm{M}$ bicuculline methiodide were included in the ECS. Records of mEPSCs were filtered at $2 \mathrm{kHz}$ and acquired with an event detection program [SCAN (synaptic current analysis), Strathclyde Electrophysiology Software (University of Strathclyde, Glasgow, Scotland), courtesy of Dr. J. Dempster]. The trigger level for the detection of events was set approximately three times higher than the baseline noise. In control neurons, 200-300 mEPSC events were collected, and, in treated neurons, 35-100 events were accumulated. Inspection of the raw data was used to eliminate any false events. All of the recordings were performed at room temperature $\left(22-24^{\circ} \mathrm{C}\right)$.

Western blot. Hippocampal neurons from sister cultures were lysed in ice-cold lysis buffer (50 mm Tris- $\mathrm{HCl}, 10 \mathrm{~mm}$ EDTA, and 1\% Triton $\mathrm{X}-100, \mathrm{pH}$ 8.0) with protease inhibitors. Lysate was cleared by centrifugation, and protein concentrations were assayed by the Bradford method (Bio-Rad, Hercules, CA). Total proteins were separated on SDS-PAGE ( $40 \mu \mathrm{g} /$ lane, unless otherwise indicated) and electroblotted onto a nitrocellulose membrane (Bio-Rad). Membranes were blocked in TBS with Tween 20 (TBST) (10 mm Tris-Cl, $150 \mathrm{~mm} \mathrm{NaCl}$, and $0.01 \%$ Tween 20, $\mathrm{pH} 8.0$ ) containing $5 \%$ nonfat dry milk powder (TBSTM) at room temperature for $1 \mathrm{hr}$ and then incubated with primary antibodies (overnight at $4^{\circ} \mathrm{C}$ ). Membranes were washed with TBST (three times for $10 \mathrm{~min}$ each) and then incubated with appropriate horseradish peroxidaseconjugated secondary antibodies in TBSTM at room temperature for 1.5 hr. After washing, bound antibodies were visualized with an ECL system (Amersham Biosciences, Buckinghamshire, UK). The following commercially available antibodies were used: anti-AChE (BD Biosciences, Franklin Lakes, NJ), anti-NR1 (BD Biosciences), anti-GluR (glutamate receptor 2), anti-GABA $A_{A}-\alpha 1$ (Chemicon, Temecula, CA), anti-PSD-95 (postsynaptic density-95) (Affinity BioReagents, Golden, CO), antineuroligin, anti-synaptophysin (Synaptic Systems, Göttingen, Germany), anti-neurexin (Santa Cruz Biotechnology, Santa Cruz, CA), and anti- $\beta$-actin (Sigma-Aldrich Canada). Quantitative analysis of Western blot was performed by means of GS-800 densitometer (Bio-Rad). Specifically, blot films were scanned, and the blot band densities were calculated using the Quantity One program (Bio-Rad). Values of the band density were normalized to the level of respective $\beta$-actin. Results were expressed as a percentage of the control band density of a specific protein.

In situ hybridization. Hippocampal cultures were hybridized, as described recently (Meshorer et al., 2004), with a 50-mer digoxigeninlabeled 2-O-methylated cRNA antisense probe (Microsynth, Balgach, Switzerland) complementary to exon 6 for AChE-S mRNA or intron 4 for the differential detection of AChE-R. After probe detection with a streptavidin-rhodamine conjugate (Amersham Biosciences, Little Chalfont, UK), confocal imaging was conducted using Image-Pro Plus 4.01 (Media Cybernetics, Silver Spring, MD). In each group, 120 cells from five cultures were examined.

Immunocytochemistry. For standard immunohistochemistry, neurons that were cultured on coverslips were fixed with 3.7\% paraformaldehyde and $4 \%$ sucrose in Dulbecco's PBS (DPBS) for $30 \mathrm{~min}$, permeabilized in $0.1 \%$ Triton X-100 for $15-30$ min, blocked in $5 \%$ horse serum or $5 \%$ BSA for $1 \mathrm{hr}$, and then incubated with primary antibodies [anti-AChE, clone 46, 1:200, BD Biosciences; anti-MAP2 (microtubule-associated protein 2), 1:400, Chemicon; and anti-synaptophysin, clone 7.2, 1:1000, Synaptic 
Systems] for $2 \mathrm{hr}$ or overnight at $4^{\circ} \mathrm{C}$. Specifically for PSD-95 staining, neuronal cultures were fixed in absolute methanol for $5 \mathrm{~min}$ at $-20^{\circ} \mathrm{C}$, blocked with BSA, and then incubated with mouse anti-PSD-95 (1:100; Affinity BioReagents) overnight at $4^{\circ} \mathrm{C}$. CY3 - or FITC-conjugated appropriate secondary antibodies were added for incubation at $4^{\circ} \mathrm{C}$ for $1 \mathrm{hr}$. Then the coverslips were rinsed with DPBS and mounted with FluoroMount G (Electron Microscopy Sciences, Hatfield, PA) for confocal microscopy. Specifically for surface staining of glutamate receptor subunits, neurons were fixed under nonpermeabilizing conditions using 3.7\% paraformaldehyde and $4 \%$ sucrose in PBS for $15 \mathrm{~min}$ at room temperature, blocked with $1 \%$ normal horse serum in PBS, and incubated (overnight at $4^{\circ} \mathrm{C}$ ) in primary antibodies [anti-GluR2, 1:2000, Chemicon; anti-NR1, clone 54.1, 1:2000, PharMingen (San Diego, CA); both of the antibodies recognize extracellular epitopes of their respective receptor subunits] in $0.1 \%$ normal horse serum in PBS. Neurons were incubated in Cy3-conjugated mouse secondary antibody (1:500; Jackson ImmunoResearch, West Grove, PA) in PBS at room temperature for $2 \mathrm{hr}$. Labeled neurons were then permeabilized with $0.1 \%$ Triton X-100 in PBS ( $5 \mathrm{~min}$ at room temperature), rinsed thoroughly, and incubated (for $2 \mathrm{hr}$ at room temperature) with the same primary antibodies used under nonpermeant conditions. FITC-conjugated secondary antibodies (1:800; Jackson ImmunoResearch) were added for incubation at $4^{\circ} \mathrm{C}$ for $1 \mathrm{hr}$. The neurons were rinsed with PBS and then mounted for confocal examination. Confocal images were taken by using an inverted microscope (Zeiss, Göttingen, Germany) with a $40 \times, 63 \times$, or $100 \times$ objective lens. The visual field was blindly moved to a random site on a cell-culture coverslip. Specific protein immunoreactive clusters in the imaging field were automatically counted and analyzed with either of the imaging programs MetaMorph (version 4.0; Universal Imaging, Downingtown, PA) or NIH Image J after setting a threshold of fluorescent intensity that was slightly lower than that in the dendritic shaft. In each study, 20-45 imaging fields of the control and treated neurons were analyzed.

ELISAs. The change in extracellular AChE protein levels was quantified using the ELISA (colorimetric) as described previously (Lu et al., 2001), with modifications. In brief, the cultured hippocampal neurons were treated with BW284c51 on the 2nd DIC for $3 \mathrm{~d}$. To measure the membrane-bound AChE, the treated and sister-control neurons were fixed under the nonpermeabilized condition as described above. To examine the soluble AChE, the culture media taken from the BW284c51treated and sister-control neurons were put in uncoated dishes (Nunc, Roskilde, Denmark) that were kept still at $4^{\circ} \mathrm{C}$ for $24 \mathrm{hr}$. After removing the media, the neuronal culture coverslips and the medium-coated dishes were gently rinsed with PBS and then blocked with $2 \%$ BSA at $4{ }^{\circ} \mathrm{C}$ for $1 \mathrm{hr}$. The coverslips and dishes were incubated with the anti-AChE monoclonal antibody (1:400; BD Biosciences) overnight. After incubation with corresponding HRP-conjugated secondary antibody (Amersham Biosciences, Little Chalfont, UK), HRP substrate o-phenylenediamine (Sigma-Aldrich Canada) was added to produce a color reaction. The optical density (OD) $(450 \mathrm{~nm})$ was measured using a spectrophotometer (Ultrospec 1000; Amersham Biosciences, Cambridge, UK). After subtraction of the background reading, the AChE-mediated OD change was presented as a percentage of the colorimetric reading from the matched control.

Statistical analysis. Unless specified otherwise, statistical analysis was performed with SigmaPlot software (SPSS, Chicago, IL). Data were expressed as mean \pm SEM and examined using Student's unpaired or paired $t$ tests whenever appropriate. A $p$ value of $<0.05$ was considered significant.

\section{Results}

\section{Progressive decline of AChE during synaptogenesis}

Accumulated evidence suggests that AChE plays a critical role in the regulation of the cytoarchitecture of developing neurons (Koenigsberger et al., 1997; Grifman et al., 1998; Bigbee et al., 2000; De Jaco et al., 2002). To further study the morphogenic role of AChE and to address the inter-relationship among AChE expression levels, neurite growth, and glutamatergic functions in developing neurons, we initially measured the cell capacitance, glutamate-evoked currents, and spontaneous EPSCs, using whole-cell recordings, as well as protein levels of AChE and several synaptic proteins by means of Western blot in hippocampal neurons on the 1st, 3rd, 5th, and 7th DIC, respectively. As expected, along with the growth of neurites, both cell capacitance (Fig. $1 A$ ) and glutamate-evoked currents (Fig. $1 B$ ) progressively increased. Although detectable spontaneous EPSCs appeared in some neurons as early as the 5th DIC, the frequency and amplitude of repetitive EPSC bursts increased dramatically from the 6th to 12 th DIC (Fig. 1C), indicating that this period is a critical stage for hippocampal neurons to form and maturate functional synapses under the present culture condition. Consistent with the continuous increase in glutamatergic synaptic activities, total protein levels of the NMDA receptor 1 (NMDR1) subunit of glutamate receptors, synaptophysin, and neuroligin raised steadily during the developmental stage, whereas the AChE level declined gradually (Fig. 1D).

The cellular and subcellular distribution patterns of AChE in these developing neurons were assessed using immunocytochemistry (Fig. $1 E$ ). Under our culture conditions, AChE immunoreactivity was detected in the majority, if not all, of hippocampal neurons that were characteristically immunolabeled by MAP2, a dendritic cytoarchitecture marker of neuronal cells (Folkerts et al., 1998) (Fig. 1E). From the 3rd to 5th DIC, the AChE protein appeared in the perikarya and dendritic neurites of all of the pyramidal neurons ( $n=3$ batches of cultures). A highdensity staining of AChE was particularly found in all observed MAP2-positive dendritic growth cones, the highly motile structure at the growing end of neuronal processes (Fig. $1 E$ ), supporting the notion that $\mathrm{AChE}$ plays a role in dendritic neurite outgrowth of developing neurons. In neurons on the 7 th $(n=3$ batches of cultures) or the 12th ( $n=3$ batches of cultures) DIC, the fine branches of dendritic neurites became dense, but the majority of growth cones disappeared (Fig. $1 \mathrm{E}$, bottom row). Concurrently, the immunoreactivity of AChE in dendritic neurites decreased drastically and was limited to only the perikarya of the neurons (Fig. 1E).

\section{PAS blockade impairs glutamate receptor function}

Effects of the peripheral ligands of AChE on neuronal functions were examined, because the peripheral blockade of AChE inhibits neurite outgrowth (Layer et al., 1993; Dupree and Bigbee, 1994; Day and Greenfield, 2002) and alters the morphology of other cells (Calderon et al., 1998). On the 3rd or the 5th DIC, the neurons were treated with BW284c51, a membrane-impermeable, highly selective PAS inhibitor-ligand of AChE. Three days later (at the 6th or the 8th DIC), we measured glutamate receptormediated currents in the treated neurons compared with the sister controls. We found that currents evoked by fast application of glutamate, NMDA, or AMPA (100 $\mu \mathrm{M}$, respectively) were greatly and similarly reduced in the treated neurons (Fig. $2 A, B$ ). In contrast, currents evoked by GABA $(200 \mu \mathrm{M})$ remained unchanged (Fig. 2C). Acute application of BW284c51 up to $100 \mu \mathrm{M}$ did not affect the glutamate receptor-mediated current (data not shown), indicating that the effect of BW284c51 on glutamate receptor function was not caused by a direct action on these receptorgated channels but involved a cellular response.

To determine whether the effect of BW284c51 was mediated by cholinergic signaling pathways, we treated the neurons with AChR agonists and antagonists, as well as distinct AChE inhibitors in the same way as with BW284c51. The effect of BW284c51 persisted in the presence of the muscarinic and nicotinic AChR antagonists atropine $(10 \mu \mathrm{M})$ and mecamylamine $(10 \mu \mathrm{M})$. Fur- 

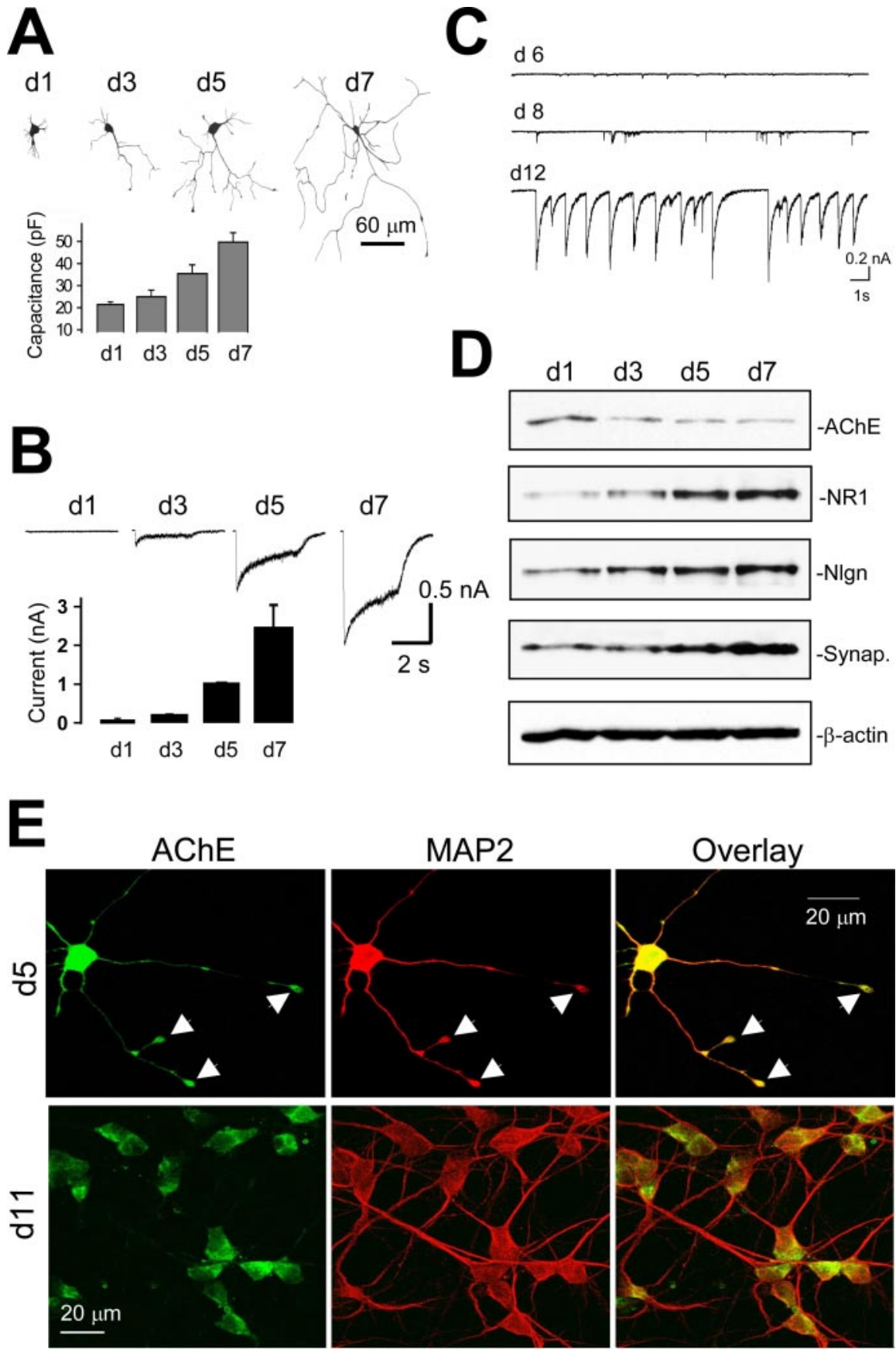

Figure 1. Progressive decline of AChE expression during hippocampal neuronal development. $A$, Shown are camera lucida drawings of four representative hippocampal neurons on the 1st, 3rd, 5th, and 7th DIC. Plotted data show that, along with the growth of neurites, the capacitance of neurons gradually increases. $B$, Representative traces and plotted data of glutamate-evoked currents recorded in neurons on the 1st, $3 \mathrm{rd}$, 5 th, and $7 \mathrm{th}$ DIC are exhibited. C, Representative records of spontaneous EPSCs on the 6th, 8th, and 12th DIC (recorded in the presence of $25 \mu \mathrm{m}$ bicuculline). D, Protein blots of AChE, NMDAR1 (NR1), neuroligin (NIgn), and synaptophysin (Synap.) from the total cell lysate of hippocampal neurons on the 1st, 3rd, 5th, and 7th DIC are shown. $E_{\text {, }}$ Confocal microscopic pictures show neurons that are immunostained for AChE and MAP2. Top row, A single neuron on the 5th DIC is shown for a clear demonstration of subcellular structures. Note the high immunoreactivity of AChE in the dendrites and growth cones (as indicated by arrows). Bottom row, Neurons on the 11th DIC. No growth cone is associated with the neurons. Note that lower immunoreactivity of $\mathrm{AChE}$ is detected in the perikarya but not the dendritic compartments of these neurons. Scale bars, $20 \mu \mathrm{m}$.

thermore, the AChR agonist carbachol $(50 \mu \mathrm{M})$ failed to mimic the effect of BW284c51 (Fig. 2D). The PAS inhibitors decamethonium and fasciculin II (Bourne et al., 1995), a peptidic mamba venom, induced a significant decrease in the amplitude of the glutamate receptor-mediated currents (Fig. 2E). In contrast, physostigmine, an active site AChE inhibitor, was ineffective (Fig.
$2 E)$. These combined results indicate that blockade of the PAS of AChE selectively depresses glutamate receptor functions, and the effect is independent of cholinergic functioning.

Chronic excitation of neurons negatively regulates glutamate receptor functions (Dickie et al., 1996; Shimazu et al., 1999). The BW284c51-induced impairment of glutamatergic functions, however, was maintained in the presence of the sodium channel blocker TTX (0.5-1.0 $\mu \mathrm{M})$, the competitive NMDA receptor antagonist 2-amino-5-phosphonopentanoic acid $(30 \mu \mathrm{M})$, or the competitive nonNMDA receptor antagonist 6,7,-dinitroquinoxaline-2,3-dione (20 $\mu \mathrm{M})$, ruling out the possibility that the peripheral antiAChE manipulations functioned by causing excitotoxicity to the hippocampal neurons.

\section{Peripheral blockade causes overexpression of $\mathrm{AChE}$, which is responsible for the impairment of glutamatergic function}

Specific anti-AChE treatments cause feedback upregulations of AChE expression in the brain of humans (Parnetti et al., 2002; Darreh-Shori et al., 2004) and mice (Kaufer et al., 1998). We compared the level of AChE expression in control, physostigmine-treated, and BW284c51treated neurons using immunocytochemistry (Fig. 3A) and Western blot analysis (Fig. 3B). Chronic obstruction of the PAS of AChE by BW284c51, but not active site blockade by physostigmine, induced a great enhancement of AChE expression in cultured hippocampal neurons (Fig. $3 A, B)$. In addition, fluorescent in situ hybridization (FISH) using selective probes against AChE- R and -S revealed a significant increase in the expression of both AChE transcripts in neurons that were treated with BW284c51. In contrast, the active site inhibitor physostigmine had no effect on either isoform of the two AChE transcripts (Fig. 3C). Confocal microscopy quantification of the labeling density in the somatic area of BW284c51-treated neurons showed significant increases in AChE-R and -S mRNAs (Fig. 3D). The BW284c51-induced increment of the two AChE transcripts could be blocked by cotreatment of the neurons with EN101 (12 $\mu \mathrm{g} / \mathrm{ml}$ ) (Fig. $3 D$ ), an antisense agent targeted at exon 2 of the AChE mRNA transcript (Shohami et al., 2000; Brenner et al., 2003). Altogether, these data demonstrate that a blockade of the PAS increases the expression of AChE.

To find out whether the PAS blockade-induced depression of glutamatergic function was caused by the overexpression of AChE, we treated neurons with BW284c51 together with the 
A
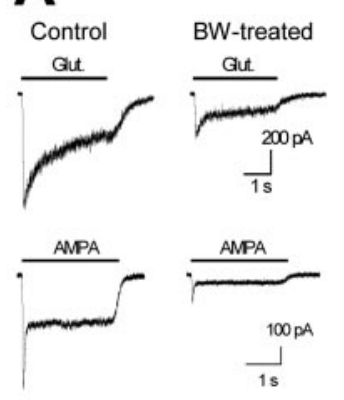

NMDA

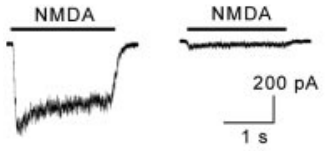

D

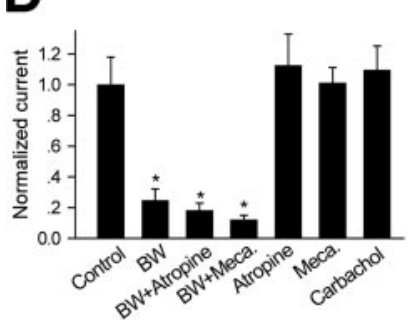

E

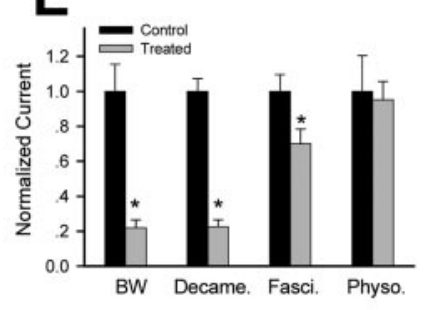

Figure 2. Chronic PAS blockade of AChE decreases glutamate receptor-mediated currents independently of cholinergic activation. $A$, Representative traces of transmembrane currents evoked by fast application of glutamate (Glut.), AMPA, and NMDA in control and BW284c51treated (BW; $5 \mu \mathrm{M}$ ) neurons. B, BW284C51 treatment induces similar reductions in the current amplitudes of NMDA and AMPA currents. Plotted data show the normalized currents (normalized to the mean value of the amplitude of peak currents) evoked by glutamate, AMPA, and NMDA in control (Ctrl) and BW284c51-treated neurons $\left(I_{\text {glut }}=38.7 \pm 6.7 \%\right.$ of control, $n=6$, $p<0.001 ; I_{\mathrm{AMPA}}=36.2 \pm 13.9 \%$ of control, $n=5, p<0.05 ; I_{\mathrm{NMDA}}=45.6 \pm 13.3 \%$ of control, $n=5, p<0.05)$. C, GABA-evoked currents are not changed by BW284c51 (10 $\mu \mathrm{M})$ treatment. $D$, Plotted values show normalized glutamate currents recorded from relevant controls and neurons treated with different AChE inhibitors [BW284c51 (5 $\mu \mathrm{m}), 21.9 \pm 4.7 \%$ of control, $n=8, p<0.001$; decamethonium $(100 \mu \mathrm{M}), 22.6 \pm 3.9 \%$ of control, $n=9, p<$ 0.0001; fasciculin-II (100 nm), $70.0 \pm 8.3 \%$ of control, $n=10, p<0.05$; physostigmine (10 $\mu \mathrm{M}), 95.2 \pm 10.5 \%$ of control, $n=7, p=0.84]$. E, Normalized peak amplitudes of glutamate currents recorded from neurons with different treatments (BW284c51, 24.6 $\pm 7.6 \%$ of control, $n=6, p<0.005$; BW284c51 plus atropine, $18.1 \pm 4.8 \%$ of control, $n=6, p<0.001$; BW284c51 plus mecamylamine, $12.1 \pm 2.8 \%$ of control, $n=6, p<0.001$; atropine, $113 \pm$ $20 \%$ control, $n=6, p=0.65$; mecamylamine, $101 \pm 10 \%$ control, $n=6, p=0.95$; carbachol, $109 \pm 15.6 \%$ control, $n=6, p=0.70$ ). Meca, Mecamylamine; Decame, decamethonium; Physo, physostigmine.

AChE antisense EN101 $(12 \mu \mathrm{g} / \mathrm{ml})$ and examined the glutamateevoked currents in the treated neurons and relevant controls. Indeed, attenuation of AChE expression by EN101 (Galyam et al., 2001), but not by the inverse oligonucleotide INV101 $(12 \mu \mathrm{g} / \mathrm{ml})$, significantly limited the BW284c51-induced suppression of glutamate currents (Fig. 3E), indicating that AChE overexpression disrupts glutamatergic functions. Different AChE variants in the brain either bind to the cell membrane via specific anchors or remain as soluble isoforms in the extracellular fluid (Massoulie, 2002). By means of the ELISA, we quantified the PAS blockadeinduced changes in extracellular AChE protein levels. We found that the PAS blockade by BW284c51 significantly increased both the membrane-bound (Fig. 3F1) and soluble (Fig. 3F2) extracellular AChE, suggesting that excess AChE disrupts glutamatergic functions at least partially through extracellular interactions. To prove this postulation, we treated the cultured neurons with an excessive amount $(0.5-3.0 \mathrm{U} / \mathrm{ml})$ of human $\mathrm{AChE}$ in the presence of physostigmine for $3 \mathrm{~d}$. The amplitude of glutamate currents in AChE-treated neurons was significantly reduced compared with the control and physostigmine-treated neurons (Fig. 3G), indicating that excess extracellular AChE interferes with glutamatergic functions.

\section{PAS blockade reduces surface glutamate receptors}

Others have shown that the PAS blockade of AChE inhibits neurite outgrowth of hippocampal neurons (Koenigsberger et al., 1997; Bigbee et al., 2000; Day and Greenfield, 2002). In our experiments, treatment of hippocampal neurons with BW284c51, but not physostigmine, reduced the fine branches of neurites of the cultured neurons (Fig. 4A). This raised the question of whether the reduction in glutamate receptor-mediated currents was simply caused by the decrease in the total surface area of the treated neurons. To address this question, we further analyzed the current density (current amplitude/cell capacitance; $\mathrm{pA} / \mathrm{pF}$ ) in neurons on different culture days. The current density was significantly reduced in BW284c51-treated neurons compared with relevant control neurons (Fig. $3 H$ ). This finding suggests that the decrease in glutamate-evoked currents under peripheral blockade is at least partially caused by a reduction in the density of surface glutamate receptors and does not reflect a general decrease in cell surface area.

We next assessed the surface glutamate receptors by immunolabeling the NMDAR1 and GluR2 subunits of glutamate receptors in BW284c51-treated and control neurons under nonpermeabilized and then permeabilized conditions (Fig. 4A). Nonpermeated cells (middle) exhibited neurite-associated clusters of the NMDAR1 (Fig. 4A1) and GluR2 (Fig. 4A2) subunits, whereas permeated cells (left) displayed immunoreactivity of the two glutamate receptor proteins in the perikarya and dendritic compartments of the neurons, particularly the spines. After BW284c51 treatment, the number of surface clusters, but not the density of intracellular immunoreactivity, of both NMDAR1 and GluR2 was significantly reduced (Fig. $4 A, B$ ), demonstrating that the peripheral blockade of AChE reduces incorporation of glutamate receptors into the cell surface plasma membrane. Moreover, the BW284c51 treatment decreased the fine, but not the main, branches of dendrites, as well as the numbers of glutamatereceptor-immunoreactive spines (Fig. 4A1,A2, left). These data were compatible with the finding of loss of spines in transgenic mice overexpressing AChE-S (Beeri et al., 1997). Remarkably, the treatment drastically decreased the density of surface glutamate receptor clusters on the main dendritic branches (Fig. 4A1,A2, middle), demonstrating that blocking the PAS of AChE reduces not only the total number, but also the density, of surface glutamate receptors.

The reduction in surface glutamate receptors could potentially reflect attenuated synthesis of glutamate receptor proteins. However, immunoblot quantification revealed that both the GluR2 and NMDAR1 protein subunits in the treated neurons were greatly increased compared with controls, indicating an intracellular accumulation of these proteins (Fig. 4C). In contrast, the $\alpha 1$-subunit of $\mathrm{GABA}_{\mathrm{A}}$ receptors remained unchanged (Fig. $4 D)$. Together with the finding that BW284c51 treatment depressed the glutamate-evoked but not GABA-evoked currents (Fig. 2), these results suggest that the PAS blockade-induced overexpression of AChE selectively impairs the targeting of glutamate receptors. 

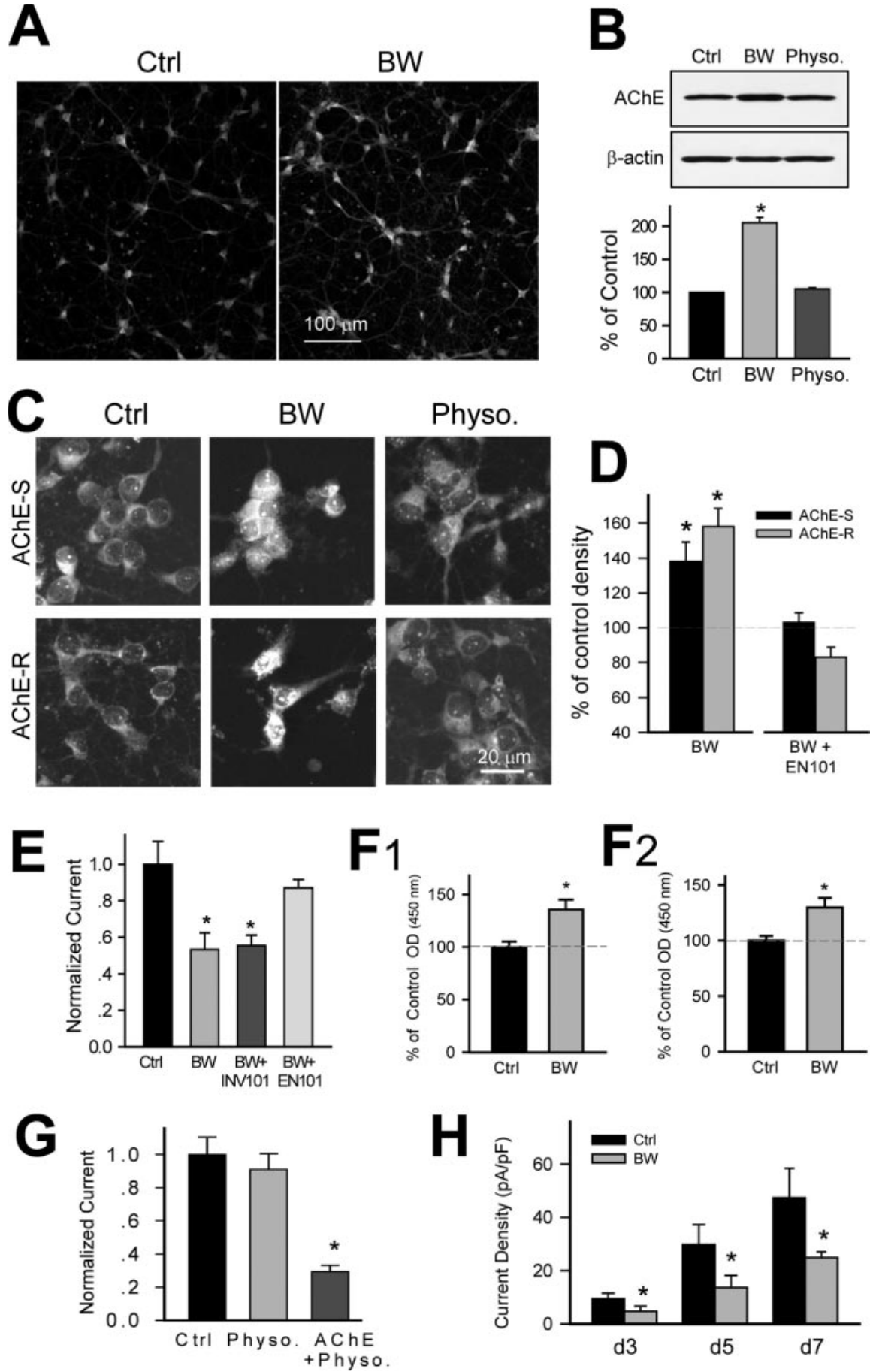

Figure 3. PAS blockade of AChE induces AChE overexpression, which causes depression of glutamate receptor functions. $A$, Representative confocal microscopy graphs of control (Ctrl) and BW284c51-treated (BW) neurons, immunocytochemically stained for AChE. Neurons were treated with $10 \mu \mathrm{m}$ BW284c51 on the 6th DIC and stained on the 9th DIC. Scale bar, $100 \mu \mathrm{m}$. B, Western blot of AChE from the total cell lysate of control, BW284c51-treated $(5 \mu \mathrm{M})$, and physostigmine-treated (Physo.;10 $\mu \mathrm{m}$ ) neurons (BW284c51, $205 \pm 8.0 \%$ of control; physostigmine, $105.5 \pm 1.5 \%$ of control). C, FISH with selective probes reveals a significant increase in -R and -S AChE mRNAs in BW284c51-treated, but not physostigmine-treated, neurons. Scale bar, $20 \mu \mathrm{m}$. D, The antisense agent EN101 efficiently blocks the BW284c51induced increase of AChE-S and -R mRNA levels (BW284c51 only: - S mRNA, $138 \pm 12 \%$ of control; $-R$ mRNA, $158 \pm 11 \%$ of control; $n=120$ cells in each group, from 5 cultures; $p<$ 0.03 in both groups) (BW284c51 plus EN101: -S mRNA, $103 \pm 5.5 \%$ of control; - R mRNA, $81 \pm 5 \%$ of control; $n=$ 40 cells, from 4 cultures). $E$, The AChE antisense EN101 prevents the BW284c51-induced depression of NMDA currents (BW284c51 only, $53.2 \pm 9.2 \%$ of control, $n=5, p<0.05$; BW284c51 plus INV101, $55.4 \pm 5.8 \%$ of control, $n=9, p<$ 0.05 ; BW284c51 plus EN101, $86.9 \pm 4.9 \%$ of control, $n=6$, $p=0.67) . F$, ELISA reveals that the BW284c51 treatment increases the membrane-bound AChE [FT; BW284c51 (3 $\mu \mathrm{m})=135.6 \pm 9.3 \%$ of control; $n=5$ coverslips of cells; $p<0.05]$ and the soluble AChE in the medium [F2; BW284c51 (3 $\mu \mathrm{m}), 129.9 \pm 8.4 \%$ of control; $n=8$ sets of medium samples; $p<0.05]$. G, Administration of exogenous soluble human $\mathrm{AChE}(3 \mathrm{U} / \mathrm{ml})$ in the culture reduces the amplitude of glutamate currents (physostigmine control, $90.9 \pm 9.6 \%$ of control, $n=11, p=0.54$; AChE plus physostigmine, $29.3 \pm 3.9 \%$ of control, $n=11, p<0.0001)$. $H$, Cell capacitance and glutamate currents in BW284c51treated $(5 \mu \mathrm{m} ; 3 \mathrm{~d}$ ) and matched-control neurons on the $1 \mathrm{st}$, 5th, and 7th DIC. BW284c51 treatment significantly reduces glutamate-current density $(\mathrm{pA} / \mathrm{pF} ; \mathrm{d} 3$ control, $9.4 \pm 2.0$, $n=6 ; \mathrm{BW} 284 \mathrm{c} 51,4.8 \pm 1.8, n=9 ; \mathrm{d} 5$ control, $29.8 \pm 7.5$, $n=6 ;$ BW284c51, $13.7 \pm 4.5, n=9 ; \mathrm{d} 7$ control, $47.4 \pm$ $11.0, n=6$; BW284c51, 24.9 $\pm 2.2, n=6) .{ }^{*} p<0.05$.

\section{Reduction in the number of synapses by blockade of the PAS}

\section{of AChE}

Nearly all excitatory input in the hippocampus impinges on dendritic spines (Zhang and Benson, 2000). As shown in Figure 4A, the PAS blockade of AChE reduced dendritic spines and surface glutamate receptors, suggesting an interruption of synaptic formation or maintenance. To test this, we labeled the presynaptic marker synaptophysin and the excitatory postsynaptic marker PSD-95 using immunocytochemistry (Fig. 5). We found that BW284c51 treatment greatly decreased the clusters of PSD-95 (Fig. 5A) and synaptophysin (Fig. 5B,D), demonstrating a decrease in the number of synapses. Interestingly, Western blot revealed a significant increase in total protein levels of both synaptic proteins (Fig. 5C), further implying an interruption of synaptogenesis. To test whether the PAS blockade-induced synaptic interruption is caused by the overexpression of AChE molecules, we further assessed the number of synaptophysin clusters in neurons that were treated with BW284c51 (5 $\mu \mathrm{M})$ together with EN101 $(12 \mu \mathrm{g} / \mathrm{ml})$ or with INV101 $(12 \mu \mathrm{g} / \mathrm{ml})$ as a control. Indeed, the AChE antisense, but not the control oligonucleotide, significantly increased the number of synaptophysin clusters in the presence of BW284c51 (Fig. 5D), indicating that the PAS blockade disrupts glutamatergic synaptic structures through an overexpression of AChE. 
PAS blockade damages glutamatergic synaptic transmission

To assess the effect of the peripheral blockade of AChE on glutamatergic synaptic functions, we treated cells on the 7th DIC with BW284c51 or with physostigmine for $3 \mathrm{~d}$ and recorded mEPSCs in the treated and control neurons on the 12th DIC. Active mEPSCs were recorded in control and physostigmine-treated neurons (Fig. 6A). As expected, both the amplitude and frequency of mEPSCs in the BW284c51treated neurons were drastically reduced compared with controls (Fig. 6B, C), demonstrating that the blockade of the peripheral site of AChE impairs excitatory synaptic transmission.

\section{Alteration of neurexin and neuroligin expression by blockade of the PAS of AChE}

Transgenic mice that overexpress AChE exhibit a drastic decrease in the expression of neurexin-1 $\beta$ mRNA (Andres et al., 1997). Given that the peripheral blockade of AChE increased AChE expression, we examined the protein levels of $\beta$-neurexin and neuroligins in BW284c51-treated and control neurons using immunoblot analysis compared with controls. Neurexin levels were drastically decreased, unlike neuroligin levels, which greatly increased in the treated neurons (Fig. 7). This finding suggests that the altered expression of neurexin and neuroligin may be involved in the impairment of excitatory synaptic structures and functions.

\section{Discussion}

This study presents two closely related findings. First, the expression level of AChE gradually declines during the period of synaptogenesis. Second, a blockade of the peripheral site of AChE induces overexpression of $\mathrm{AChE}$, which impairs glutamatergic synaptic structures and transmission.

The expression level of AChE is high in the embryonic nervous system, with a transient peak during the period of neural differentiation and neuritogenesis before synaptogenesis (Layer, 1990, 1991), and gradually declines during postnatal maturation (Forloni et al., 1989; Geula et al., 1995). The temporal pattern of AChE expression suggests a regulatory role of the molecule in neuronal development. The hippocampal neurons are heavily innervated by cholinergic axonal neuropils (Frotscher and Leranth, 1985; Aznavour et al., 2002) from the basal forebrain, but a small number of neurons in the hippocampus are cholinergic (Deller et al., 1999; Aznavour et al., 2002). A previous histochemical study indicates that AChE exists in non-

B
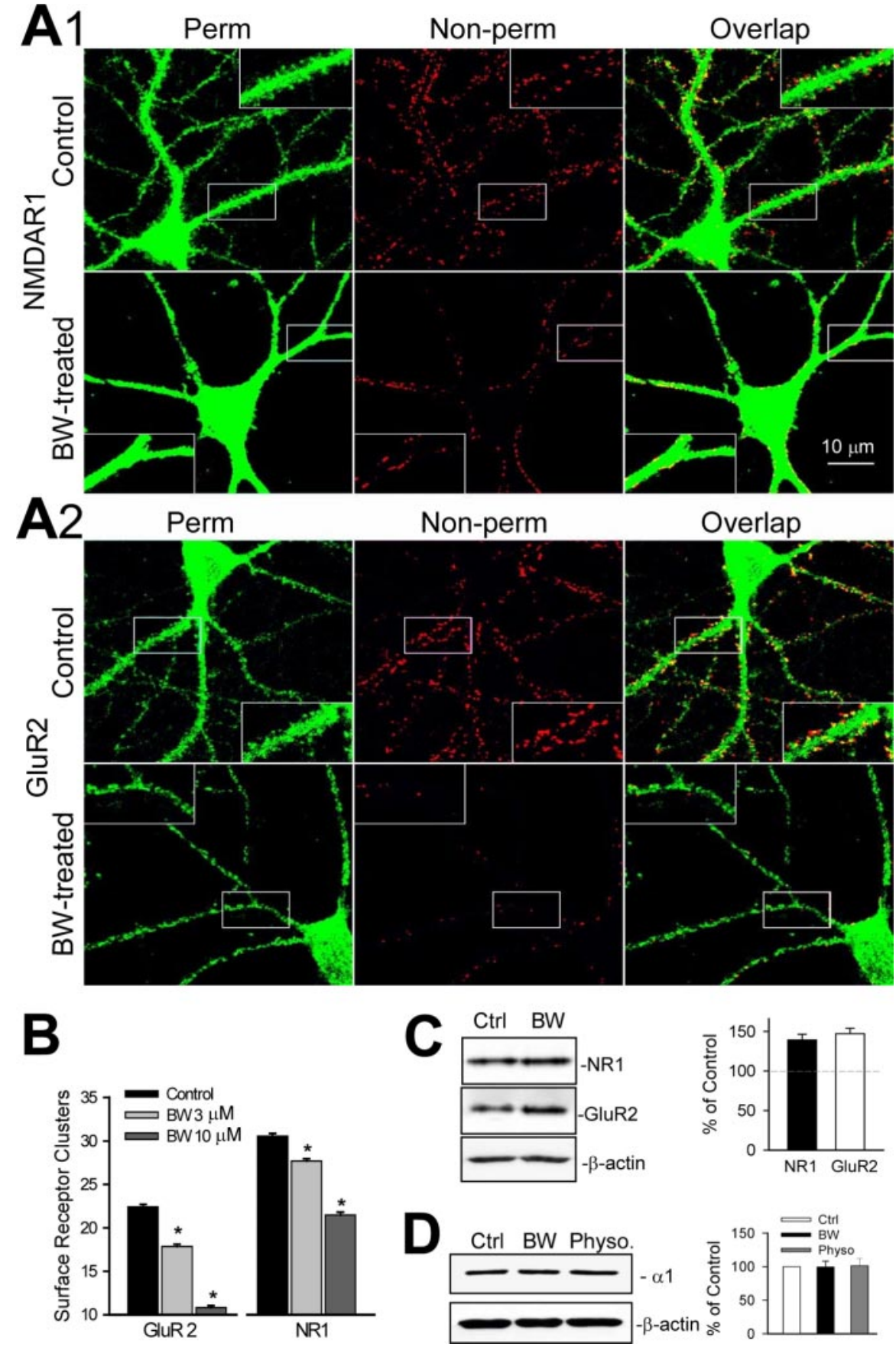

Figure 4. Reduction in dendritic spines and surface glutamate receptors under PAS blockade. $A$, Representative confoca microscopic photos show immunocytochemical staining of NR1 (A1) and GluR2 (A2) subunits of glutamate receptors under nonpermeated (Non-perm; middle) and permeated (Perm; left) conditions in control (top row) and BW284c51-treated (BW) neurons. Surface NR1 and GluR2 are labeled under nonpermeated conditions. Both NR1 and GluR2 are located in the dendritic spines; thus, under the permeated conditions, dendritic spines are labeled by NR1 and GluR2 staining. Note the insets that show decreases in dendritic spines and surface glutamate receptors in BW284c51-treated neurons compared with controls. Scale bar (in A1): A1, A2, $10 \mu \mathrm{m}$. B, Plotted data show surface receptor clusters in control and BW284c51-treated (5 $\mu \mathrm{m}$ ) neurons. C, Immunoblot of NR1 and GluR2 from total cell lysate of control (Ctrl) and BW284c51-treated neurons. BW284c51 treatment increases the total cellular proteins of glutamate receptor subunits (NR1, $139 \pm 7.5 \%$ of control, $n=3, p<0.05$; GluR2, $147 \pm 7.0 \%$ of control, $n=3, p<0.05)$. D, Immunoblot of the $\alpha 1$ subunit of $\mathrm{GABA}_{\mathrm{A}}$ receptor from the total cell lysate of control, $\mathrm{BW} 284 \mathrm{C} 51$ treated, and physostigmine-treated (Physo.) neurons.

cholinergic hippocampal neurons (Forloni et al., 1989). Our immunocytochemistry revealed that AChE was widely expressed in cultured hippocampal neurons. Remarkably, in the early developmental stage, the hippocampal neurons presented a high immunoreactivity of AChE in the perikarya and dendritic compart- 


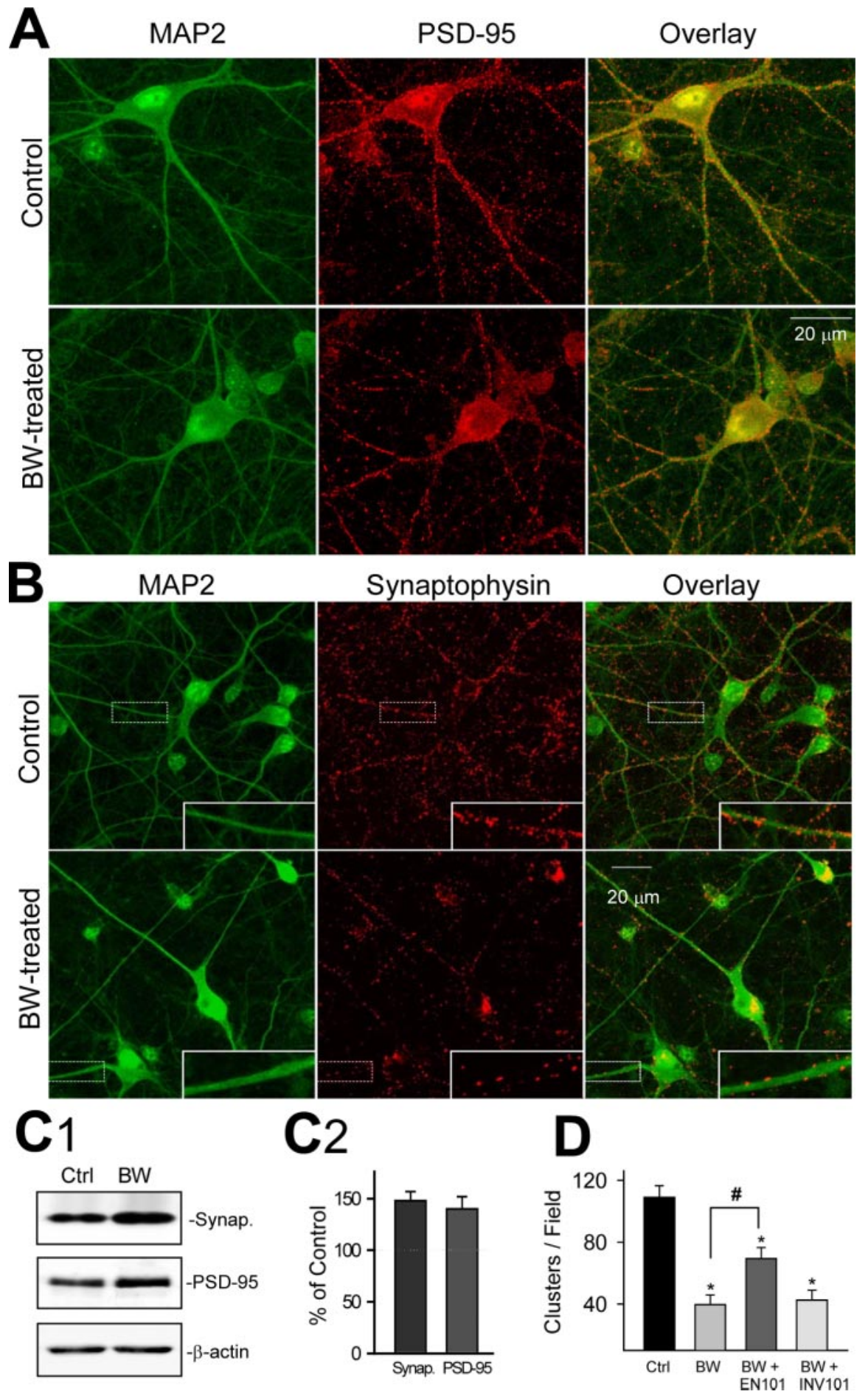

Figure 5. PAS blockade reduces the clusters of synaptophysin and PSD-95. Confocal microscopic pictures show double-label immunocytochemical staining of MAP2 together with PSD-95 $(A)$ and staining of MAP2 with synaptophysin $(B)$, showing a great reduction in numbers of excitatory synapses. PSD-95 clusters are significantly reduced in BW284c51-treated (BW) neurons compared with controls. The number of PSD-95 clusters per imaging field is reduced from $345.4 \pm 19.8$ to $215.5 \pm 31.2$ ( $p<0.05$; not plotted). Scale bars: $A, B, 20 \mu \mathrm{m}$. C, Immunoblot of synaptophysin (Synap.) and PSD-95 from the total cell lysate of control (Ctrl) and BW284C51-treated neurons (C1). BW284c51 treatment increases the total amount of synaptic proteins ( 2 ; synaptophysin, $148 \pm 9.0 \%$ of control, $n=3, p<0.05$; PSD-95, $140 \pm 12 \%$ of control, $n=3, p<0.05$ ). D, Plotted numbers of synaptophysin clusters per imaging field in neurons with different treatments. Note that the BW284c51-induced decrease in synaptophysin clusters is significantly prevented by cotreating the neurons with the AChE antisense EN101 (control, $109 \pm 7.5$; BW284c51 alone, $39.6 \pm 6.3$; BW284c51 plus EN101, $69.4 \pm 7.1$; BW284c51 plus INV101, $42.5 \pm 6.4$ ). * $p<0.05$ indicates significant difference compared with control. ${ }^{*} p<0.05$ indicates significant difference between BW284c51 and BW284c51 plus EN101. ments, particularly the dendritic growth cones (Fig. $1 E$ ). In agreement with accumulated evidence (Koenigsberger et al., 1997; Bigbee et al., 2000; De Jaco et al., 2002), our finding further indicates an upregulatory role of $\mathrm{AChE}$ in the outgrowth of dendritic cytoarchitectures. Studies in intact animals reveal that the expression levels of AChE in the cortex (Geula et al. 1993, 1995) and hippocampus (Forloni et al., 1989) vary in different subregions and decline with brain maturation. Consistent with these in vivo findings, the present study revealed that, during the period of synaptogenesis, the expression level of AChE in hippocampal neurons gradually diminished, particularly in the dendritic compartments. This finding suggests that a level of AChE in dendritic compartments is not necessary for synaptic formation. In relation to this issue, the progressive loss of dendritic spines and arborizations in cortical neurons in AChEoverexpressing transgenic mice (Beeri et al., 1997) also indicates that excessive AChE is detrimental to synaptic structures.

The PAS of AChE is fundamental for some noncatalytic functions of the enzymatic molecule. Specific site-directed mutagenesis (Shafferman et al., 1994) to reduce the negative electric field of the PAS has no effect on catalysis but changes the rate of association with the peptide ligand fasciculin (Radic et al., 1997), demonstrating that altering the PAS of AChE disrupts the interaction of AChE with other proteins. The PAS-mediated protein-protein interactions have been postulated to be involved in synaptogenesis in hippocampal neurons (Olivera et al., 2003). If this is true, an alteration of the PAS of AChE could potentially affect synaptic receptor functions. Indeed, chronic treatment of the hippocampal neurons with the membraneimpermeable PAS ligand BW284c51 and other PAS ligands greatly reduced the glutamate-, but not GABA-, evoked current in a manner independent of cholinergic functions. Remarkably, the PAS blockade altered the expression level of glutamate receptors but not $\mathrm{GABA}_{\mathrm{A}}$ receptors, suggesting a specific role of $\mathrm{AChE}$ in the regulation of glutamatergic functions in developing neurons. These results also rule out the possibility that BW284c51 causes a nonspecific toxic action but rather suggest a cellular response of these neurons to alterations of extracellular AChEs. Moreover, our immunocytochemistry studies revealed that the peripheral blockade of AChE decreased the density of surface glutamate receptors, the number of synapses, and the excitatory synaptic activities. These results demonstrate that the PAS blockade-induced im- 
pairment of glutamatergic functions is caused by an interruption of excitatory synaptic formation and/or maturation.

The observation that the PAS blockade increases the expression of AChE is of great importance, because such a blockade occurs under clinical treatments with AChE inhibitors or exposures to antiAChE agents, including pesticides and chemical warfare agents. It is known that anti-AChE exposures induce a feedback response of transcriptional activation of the ACHE gene (Soreq and Seidman, 2001). Indeed, the PAS blockade-induced destructive alterations in glutamatergic synaptic structures and functions could be partially prevented by antisense suppression of $A C H E$ gene expression, supporting the notion that the glutamatergic impairment is caused by the overexpression of AChE. This working hypothesis was supported by the finding that treating the cultured neurons with exogenous AChE significantly impaired glutamate receptor functions. Our unpublished immunocytochemical results also show that the exogenous AChE treatment reduces the clusters of the surface glutamate receptors in the neurons. Altogether, our data demonstrate that excessive extracellular AChE molecules disrupt excitatory synaptic formation or maturation. Contrary to our findings, Olivera et al. (2003) found that exposure of cultured embryonic hippocampal neurons to a low concentration (0.01-0.05 U/ml) of eel AChE in the presence of serum-containing medium increased the number of clusters of the presynaptic marker protein SV2a (synaptic vesicle protein $2 \mathrm{a}$ ) and the surface expression of AMPA-subtype, but not NMDA-subtype, glutamate receptors. These different results may reflect distinct morphogenic actions of high and low levels of AChE molecules at different developmental stages or, alternatively, involve a potential morphogenic function of the bovine AChE included in the growth medium used or the nonhomologous C-terminal domain in the eel enzyme.

The specific signaling pathway by which the PAS of AChE regulates the ACHE gene expression awaits additional experimentation. Nevertheless, the FISH analysis revealed that the PAS blockade predictably increased the levels of both the AChE-R and -S mRNA variants, indicative of an increase in both types of AChE molecules. It has been known that AChE-S forms, via C-terminal disulfide bridges, various oligomers that are anchored to distinct domains of the cell membrane through the noncatalytic subunit "proline-rich membrane anchor" (Perrier et al., 2002). In contrast, AChE-R has no such feature for multisubunit assembly and heterologous association with the anchoring subunits, thus remaining monomeric and soluble. Consistent with the finding by FISH analysis, our ELISA revealed that the PAS blockade induced a significant increase in both the membrane-bound AChE and the soluble AChE in the medium. The noncatalytic actions of AChE are related to its specific subcellular localization (Massoulie, 2002). Therefore, additional studies are
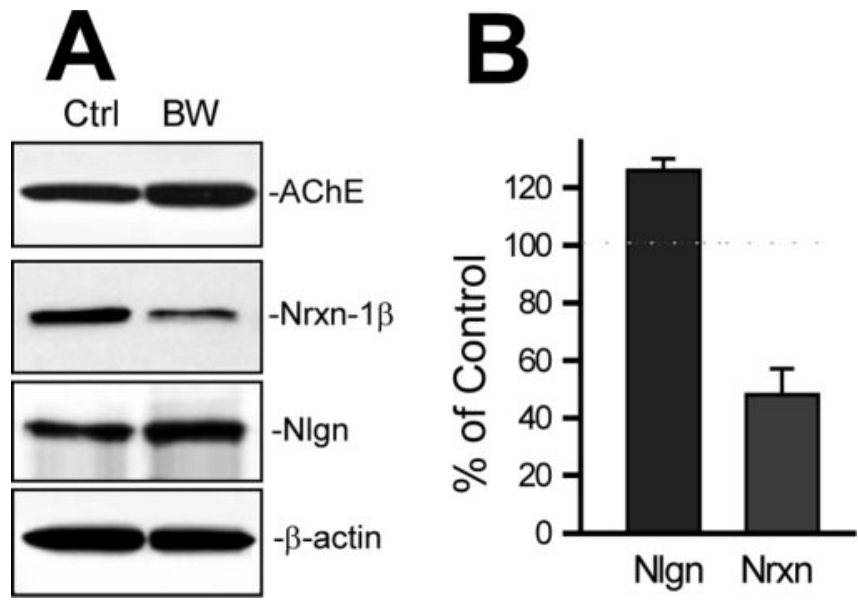

Figure 7. PAS blockade alters the expression of neurexin-1 $\beta$ (Nrxn) and neuroligins (Nlgn). $A$, Immunoblot of neurexin- $1 \beta$ and neuroligins from the total cell lysate of control (Ctrl) and BW284c51-treated (BW) neurons. $B$, The plot of the normalized blot density (neuroligin, $126 \pm$ $4.0 \%$ of control, $n=3, p<0.05$; neurexin, $48 \pm 9.0 \%$ of control, $n=4, p<0.05$ ). 
required to identify specific roles of the soluble and membranebound AChE variants in the regulation of synaptogenesis.

How can excessive AChE molecules selectively interrupt glutamatergic synaptic functions? One possible signaling pathway by which AChE alters synaptic formation or maintenance is to influence the neuroligin-neurexin junction. Neuroligins are specifically located in the postsynaptic membrane of brain excitatory synapses (Song et al., 1999). In the postsynaptic compartment, neuroligin is tied intracellularly by PSD-95, which in turn, interacts with the NR2B subunit of NMDARs (Kornau et al., 1995; Sprengel et al., 1998; Washbourne et al., 2002; Shiraishi et al., 2003) and regulates synaptic targeting of AMPA receptors (Chetkovich et al., 2002; Schnell et al., 2002). The interaction between neurexin and neuroligin induces presynaptic vesicle clustering and triggers differentiation (Scheiffele et al., 2000) and assembly (Dean et al., 2003) of axonal terminals, indicating a key role of the neurexin-neuroligin junction in excitatory synaptic formation and maturation. Thus, interference with the neurexin-neuroligin interaction could ultimately alter the function of glutamatergic synapses. Overexpression of AChE-S in mice suppresses neurexin- $1 \beta$ production in embryonic spinal motor neurons (Andres et al., 1997). In this study, the peripheral blockade of AChE induced an overexpression of AChE while decreasing the expression of neurexin- $1 \beta$, indicating crosstalk between the level of AChE and the expression of neurexins. Considering all of the available evidence, we propose that excess AChE depresses the expression of neurexin, reducing the formation of neurexin-neuroligin junctions at excitatory synapses, consequently causing damage to synaptic structure and function.

Our findings bear significant implications with regard to the pathogenesis of Alzheimer's disease (AD). Living neurons in early $\mathrm{AD}$ brains drop synaptic dendritic materials in the terminal segment of dendritic trees and ultimately lose certain synaptic connections in specific brain regions (Scheff and Price, 2003), resulting in cognitive decline. Mounting evidence suggests that $\mathrm{AD}$ is a result of synaptic failure (Selkoe, 2002). AChE proteins are intimately associated with the AD senile plaques and neurofibrillary tangles (Ulrich et al., 1990; Moran et al., 1993) and facilitate the growth of fibrillar $\beta$-amyloid plaques (Inestrosa et al., 1996). In addition, transgenic mice overexpressing AChE exhibit loss of dendritic spines (Beeri et al., 1997) and suffer from cognitive deficits (Beeri et al., 1995). Furthermore, when crossed with $\beta$-APP ( $\beta$-amyloid precursor protein) transgenics, the AChE transgenics develop amyloid plaques earlier than the parent strain (Rees et al., 2003). In agreement with previous findings, the current study for the first time directly demonstrated that excessive inactive AChE reduced the fine branches of neurites, interrupted the surface expression of glutamate receptors, and impaired synaptic structures and transmission in hippocampal neurons, clearly indicating that excessive AChE molecules are a harmful factor in the process of neurodegeneration.

\section{References}

Andres C, Beeri R, Friedman A, Lev-Lehman E, Henis S, Timberg R, Shani M, Soreq H (1997) Acetylcholinesterase-transgenic mice display embryonic modulations in spinal cord choline acetyltransferase and neurexin Ibeta gene expression followed by late-onset neuromotor deterioration. Proc Natl Acad Sci USA 94:8173-8178.

Aubert I, Poirier J, Gauthier S, Quirion R (1994) Multiple cholinergic markers are unexpectedly not altered in the rat dentate gyrus following entorhinal cortex lesions. J Neurosci 14:2476-2484.

Aznavour N, Mechawar N, Descarries L (2002) Comparative analysis of cholinergic innervation in the dorsal hippocampus of adult mouse and rat: a quantitative immunocytochemical study. Hippocampus 12:206-217.
Barak D, Kronman C, Ordentlich A, Ariel N, Bromberg A, Marcus D, Lazar A, Velan B, Shafferman A (1994) Acetylcholinesterase peripheral anionic site degeneracy conferred by amino acid arrays sharing a common core. J Biol Chem 269:6296-6305.

Beeri R, Andres C, Lev-Lehman E, Timberg R, Huberman T, Shani M, Soreq H (1995) Transgenic expression of human acetylcholinesterase induces progressive cognitive deterioration in mice. Curr Biol 5:1063-1071.

Beeri R, Le Novere N, Mervis R, Huberman T, Grauer E, Changeux JP, Soreq H (1997) Enhanced hemicholinium binding and attenuated dendrite branching in cognitively impaired acetylcholinesterase-transgenic mice. J Neurochem 69:2441-2451.

Bigbee JW, Sharma KV, Chan EL, Bogler O (2000) Evidence for the direct role of acetylcholinesterase in neurite outgrowth in primary dorsal root ganglion neurons. Brain Res 861:354-362.

Botti SA, Felder CE, Sussman JL, Silman I (1998) Electrotactins: a class of adhesion proteins with conserved electrostatic and structural motifs. Protein Eng 11:415-420.

Bourne Y, Taylor P, Marchot P (1995) Acetylcholinesterase inhibition by fasciculin: crystal structure of the complex. Cell 83:503-512.

Brenner T, Hamra-Amitay Y, Evron T, Boneva N, Seidman S, Soreq H (2003) The role of readthrough acetylcholinesterase in the pathophysiology of myasthenia gravis. FASEB J 17:214-222.

Brewer GJ (1995) Serum-free B27/neurobasal medium supports differentiated growth of neurons from the striatum, substantia nigra, septum, cerebral cortex, cerebellum, and dentate gyrus. J Neurosci Res 42:674-683.

Calderon FH, von Bernhardi R, De Ferrari G, Luza S, Aldunate R, Inestrosa NC (1998) Toxic effects of acetylcholinesterase on neuronal and gliallike cells in vitro. Mol Psychiatry 3:247-255.

Chetkovich DM, Chen L, Stocker TJ, Nicoll RA, Bredt DS (2002) Phosphorylation of the postsynaptic density-95 (PSD-95)/discs large/zona occludens-1 binding site of stargazin regulates binding to PSD-95 and synaptic targeting of AMPA receptors. J Neurosci 22:5791-5796.

Coleman BA, Taylor P (1996) Regulation of acetylcholinesterase expression during neuronal differentiation. J Biol Chem 271:4410-4416.

Darreh-Shori T, Hellstrom-Lindahl E, Flores-Flores C, Guan ZZ, Soreq H, Nordberg A (2004) Long-lasting acetylcholinesterase splice variations in anticholinesterase-treated Alzheimer's disease patients. J Neurochem 88:1102-1113.

Day T, Greenfield SA (2002) A non-cholinergic, trophic action of acetylcholinesterase on hippocampal neurones in vitro: molecular mechanisms. Neuroscience 111:649-656.

De Jaco A, Augusti-Tocco G, Biagioni S (2002) Alternative acetylcholinesterase molecular forms exhibit similar ability to induce neurite outgrowth. J Neurosci Res 70:756-765.

Dean C, Scholl FG, Choih J, DeMaria S, Berger J, Isacoff E, Scheiffele P (2003) Neurexin mediates the assembly of presynaptic terminals. Nat Neurosci 6:708-716.

Deller T, Katona I, Cozzari C, Frotscher M, Freund TF (1999) Cholinergic innervation of mossy cells in the rat fascia dentata. Hippocampus 9:314-320.

Dickie BG, Holmes C, Greenfield SA (1996) Neurotoxic and neurotrophic effects of chronic $N$-methyl-D-aspartate exposure upon mesencephalic dopaminergic neurons in organotypic culture. Neuroscience 72:731-741.

Dupree JL, Bigbee JW (1994) Retardation of neuritic outgrowth and cytoskeletal changes accompany acetylcholinesterase inhibitor treatment in cultured rat dorsal root ganglion neurons. J Neurosci Res 39:567-575.

Ellman GL, Courtney KD, Andres Jr V, Feather-Stone RM (1961) A new and rapid colorimetric determination of acetylcholinesterase activity. Biochem Pharmacol 7:88-95.

Folkerts MM, Berman RF, Muizelaar JP, Rafols JA (1998) Disruption of MAP-2 immunostaining in rat hippocampus after traumatic brain injury. J Neurotrauma 15:349-363.

Forloni G, Blake K, Hohmann CH, Coyle JT (1989) The postnatal expression of acetylcholinesterase in somatostatin-positive cells of mouse hippocampus. Brain Res Dev Brain Res 48:73-85.

Frotscher M, Leranth C (1985) Cholinergic innervation of the rat hippocampus as revealed by choline acetyltransferase immunocytochemistry: a combined light and electron microscopic study. J Comp Neurol 239:237-246.

Galyam N, Grisaru D, Grifman M, Melamed-Book N, Eckstein F, Seidman S, Eldor A, Soreq H (2001) Complex host cell responses to antisense sup- 
pression of ACHE gene expression. Antisense Nucleic Acid Drug Dev 11:51-57.

Geula C, Mesulam MM, Tokuno H, Kuo CC (1993) Developmentally transient expression of acetylcholinesterase within cortical pyramidal neurons of the rat brain. Brain Res Dev Brain Res 76:23-31.

Geula C, Mesulam MM, Kuo CC, Tokuno H (1995) Postnatal development of cortical acetylcholinesterase-rich neurons in the rat brain: permanent and transient patterns. Exp Neurol 134:157-178.

Grifman M, Galyam N, Seidman S, Soreq H (1998) Functional redundancy of acetylcholinesterase and neuroligin in mammalian neuritogenesis. Proc Natl Acad Sci USA 95:13935-13940.

Ichtchenko K, Hata Y, Nguyen T, Ullrich B, Missler M, Moomaw C, Sudhof TC (1995) Neuroligin 1: a splice site-specific ligand for beta-neurexins. Cell 81:435-443.

Inestrosa NC, Alvarez A, Perez CA, Moreno RD, Vicente M, Linker C, Casanueva OI, Soto C, Garrido J (1996) Acetylcholinesterase accelerates assembly of amyloid-beta-peptides into Alzheimer's fibrils: possible role of the peripheral site of the enzyme. Neuron 16:881-891.

Johnson G, Moore SW (2000) Cholinesterases modulate cell adhesion in human neuroblastoma cells in vitro. Int J Dev Neurosci 18:781-790.

Kaufer D, Friedman A, Seidman S, Soreq H (1998) Acute stress facilitates long-lasting changes in cholinergic gene expression. Nature 393:373-377.

Koenigsberger C, Chiappa S, Brimijoin S (1997) Neurite differentiation is modulated in neuroblastoma cells engineered for altered acetylcholinesterase expression. J Neurochem 69:1389-1397.

Kornau HC, Schenker LT, Kennedy MB, Seeburg PH (1995) Domain interaction between NMDA receptor subunits and the postsynaptic density protein PSD-95. Science 269:1737-1740.

Layer PG (1990) Cholinesterases preceding major tracts in vertebrate neurogenesis. BioEssays 12:415-420.

Layer PG (1991) Cholinesterases during development of the avian nervous system. Cell Mol Neurobiol 11:7-33.

Layer PG, Weikert T, Alber R (1993) Cholinesterases regulate neurite growth of chick nerve cells in vitro by means of a non-enzymatic mechanism. Cell Tissue Res 273:219-226.

Lu WY, Man H, Ju W, Trimble WS, MacDonald JF, Wang YT (2001) Activation of synaptic NMDA receptors induces membrane insertion of new AMPA receptors and LTP in cultured hippocampal neurons. Neuron 29:243-254.

Massoulie J (2002) The origin of the molecular diversity and functional anchoring of cholinesterases. Neurosignals 11:130-143.

Massoulie J, Anselmet A, Bon S, Krejci E, Legay C, Morel N, Simon S (1998) Acetylcholinesterase: C-terminal domains, molecular forms and functional localization. J Physiol (Paris) 92:183-190.

Meshorer E, Erb C, Gazit R, Pavlovsky L, Kaufer D, Friedman A, Glick D, Ben Arie N, Soreq H (2002) Alternative splicing and neuritic mRNA translocation under long-term neuronal hypersensitivity. Science 295:508-512.

Meshorer E, Toiber D, Zurel D, Sahly I, Dori A, Cagnano E, Schreiber L, Grisaru D, Tronche F, Soreq H (2004) Combinatorial complexity of 5' alternative ACHE transcripts and protein products. J Biol Chem 279:29740-29751.

Moran MA, Mufson EJ, Gomez-Ramos P (1993) Colocalization of cholinesterases with beta amyloid protein in aged and Alzheimer's brains. Acta Neuropathol (Berl) 85:362-369.

Munoz FJ, Aldunate R, Inestrosa NC (1999) Peripheral binding site is involved in the neurotrophic activity of acetylcholinesterase. NeuroReport 10:3621-3625.

Nair HK, Seravalli J, Arbuckle T, Quinn DM (1994) Molecular recognition in acetylcholinesterase catalysis: free-energy correlations for substrate turnover and inhibition by trifluoro ketone transition-state analogs. Biochemistry 33:8566-8576.

Nijholt I, Farchi N, Kye M, Sklan EH, Shoham S, Verbeure B, Owen D, Hochner B, Spiess J, Soreq H, Blank T (2004) Stress-induced alternative splicing of acetylcholinesterase results in enhanced fear memory and long-term potentiation. Mol Psychiatry 9:174-183.

Olivera S, Rodriguez-Ithurralde D, Henley JM (2003) Acetylcholinesterase promotes neurite elongation, synapse formation, and surface expression of AMPA receptors in hippocampal neurones. Mol Cell Neurosci 23:96-106.

Parnetti L, Amici S, Lanari A, Romani C, Antognelli C, Andreasen N, Mint- hon L, Davidsson P, Pottel H, Blennow K, Gallai V (2002) Cerebrospinal fluid levels of biomarkers and activity of acetylcholinesterase (AChE) and butyrylcholinesterase in $\mathrm{AD}$ patients before and after treatment with different AChE inhibitors. Neurol Sci 23 [Suppl 2]:S95-S96.

Perrier AL, Massoulie J, Krejci E (2002) PRiMA: the membrane anchor of acetylcholinesterase in the brain. Neuron 33:275-285.

Radic Z, Kirchhoff PD, Quinn DM, McCammon JA, Taylor P (1997) Electrostatic influence on the kinetics of ligand binding to acetylcholinesterase. Distinctions between active center ligands and fasciculin. J Biol Chem 272:23265-23277.

Rasool CG, Svendsen CN, Selkoe DJ (1986) Neurofibrillary degeneration of cholinergic and noncholinergic neurons of the basal forebrain in Alzheimer's disease. Ann Neurol 20:482-488.

Rees T, Hammond PI, Soreq H, Younkin S, Brimijoin S (2003) Acetylcholinesterase promotes beta-amyloid plaques in cerebral cortex. Neurobiol Aging 24:777-787.

Saxena A, Hur RS, Luo C, Doctor BP (2003) Natural monomeric form of fetal bovine serum acetylcholinesterase lacks the C-terminal tetramerization domain. Biochemistry 42:15292-15299.

Scheff SW, Price DA (2003) Synaptic pathology in Alzheimer's disease: a review of ultrastructural studies. Neurobiol Aging 24:1029-1046.

Scheiffele P, Fan J, Choih J, Fetter R, Serafini T (2000) Neuroligin expressed in nonneuronal cells triggers presynaptic development in contacting axons. Cell 101:657-669.

Schlaggar BL, De Carlos JA, O’Leary DD (1993) Acetylcholinesterase as an early marker of the differentiation of dorsal thalamus in embryonic rats. Brain Res Dev Brain Res 75:19-30.

Schnell E, Sizemore M, Karimzadegan S, Chen L, Bredt DS, Nicoll RA (2002) Direct interactions between PSD-95 and stargazin control synaptic AMPA receptor number. Proc Natl Acad Sci USA 99:13902-13907.

Scholl FG, Scheiffele P (2003) Making connections: cholinesterase-domain proteins in the CNS. Trends Neurosci 26:618-624.

Selkoe DJ (2002) Alzheimer's disease is a synaptic failure. Science 298:789-791.

Shafferman A, Ordentlich A, Barak D, Kronman C, Ber R, Bino T, Ariel N, Osman R, Velan B (1994) Electrostatic attraction by surface charge does not contribute to the catalytic efficiency of acetylcholinesterase. EMBO J 13:3448-3455.

Sharma KV, Koenigsberger C, Brimijoin S, Bigbee JW (2001) Direct evidence for an adhesive function in the noncholinergic role of acetylcholinesterase in neurite outgrowth. J Neurosci Res 63:165-175.

Shimazu S, Katsuki H, Akaike A (1999) Deprenyl rescues dopaminergic neurons in organotypic slice cultures of neonatal rat mesencephalon from $N$-methyl-D-aspartate toxicity. Eur J Pharmacol 377:29-34.

Shiraishi Y, Mizutani A, Mikoshiba K, Furuichi T (2003) Coincidence in dendritic clustering and synaptic targeting of homer proteins and NMDA receptor complex proteins NR2B and PSD95 during development of cultured hippocampal neurons. Mol Cell Neurosci 22:188-201.

Shohami E, Kaufer D, Chen Y, Seidman S, Cohen O, Ginzberg D, MelamedBook N, Yirmiya R, Soreq H (2000) Antisense prevention of neuronal damages following head injury in mice. J Mol Med 78:228-236.

Song JY, Ichtchenko K, Sudhof TC, Brose N (1999) Neuroligin 1 is a postsynaptic cell-adhesion molecule of excitatory synapses. Proc Natl Acad Sci USA 96:1100-1105.

Soreq H, Seidman S (2001) Acetylcholinesterase-new roles for an old actor. Nat Rev Neurosci 2:294-302.

Sprengel R, Suchanek B, Amico C, Brusa R, Burnashev N, Rozov A, Hvalby O, Jensen V, Paulsen O, Andersen P, Kim JJ, Thompson RF, Sun W, Webster LC, Grant SG, Eilers J, Konnerth A, Li J, McNamara JO, Seeburg PH (1998) Importance of the intracellular domain of NR2 subunits for NMDA receptor function in vivo. Cell 92:279-289.

Ulrich J, Meier-Ruge W, Probst A, Meier E, Ipsen S (1990) Senile plaques: staining for acetylcholinesterase and A4 protein: a comparative study in the hippocampus and entorhinal cortex. Acta Neuropathol (Berl) 80:624-628.

Washbourne P, Bennett JE, McAllister AK (2002) Rapid recruitment of NMDA receptor transport packets to nascent synapses. Nat Neurosci 5:751-759.

Zhang W, Benson DL (2000) Development and molecular organization of dendritic spines and their synapses. Hippocampus 10:512-526. 